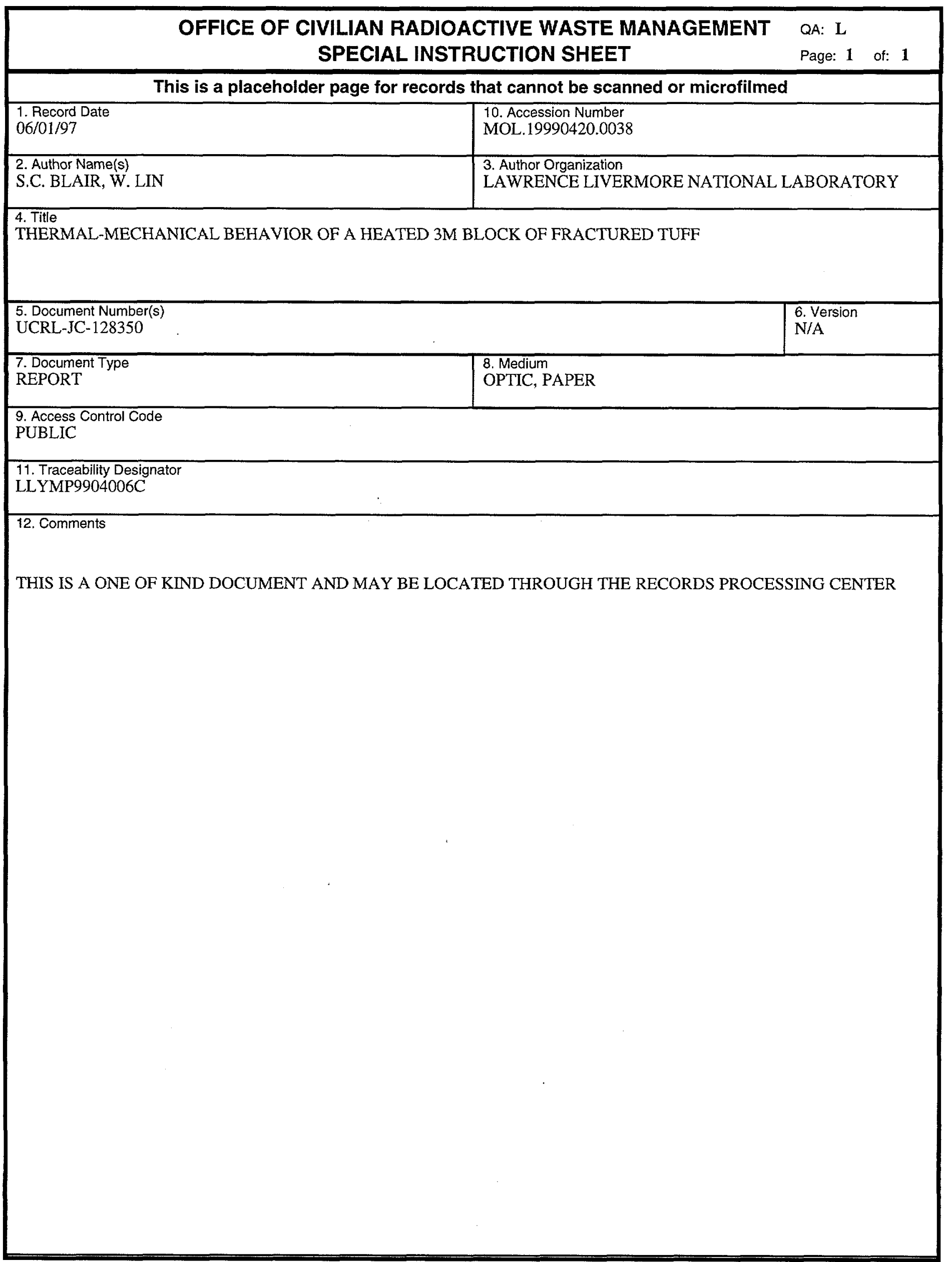


LLYMP9904006C C

\title{
Thermal-Mechanical Behavior of a Heated 3m Block of Fractured Tuff
}

\author{
S.C. Blair
}

W. Lin

This paper was prepared for submittal to the

Third International Conference on Mechanics of Jointed and Faulted Rock, 3D Modeling, Time Dependence and Complex Interaction

Vienna, Austria

April 6-9, 1998

June 1997

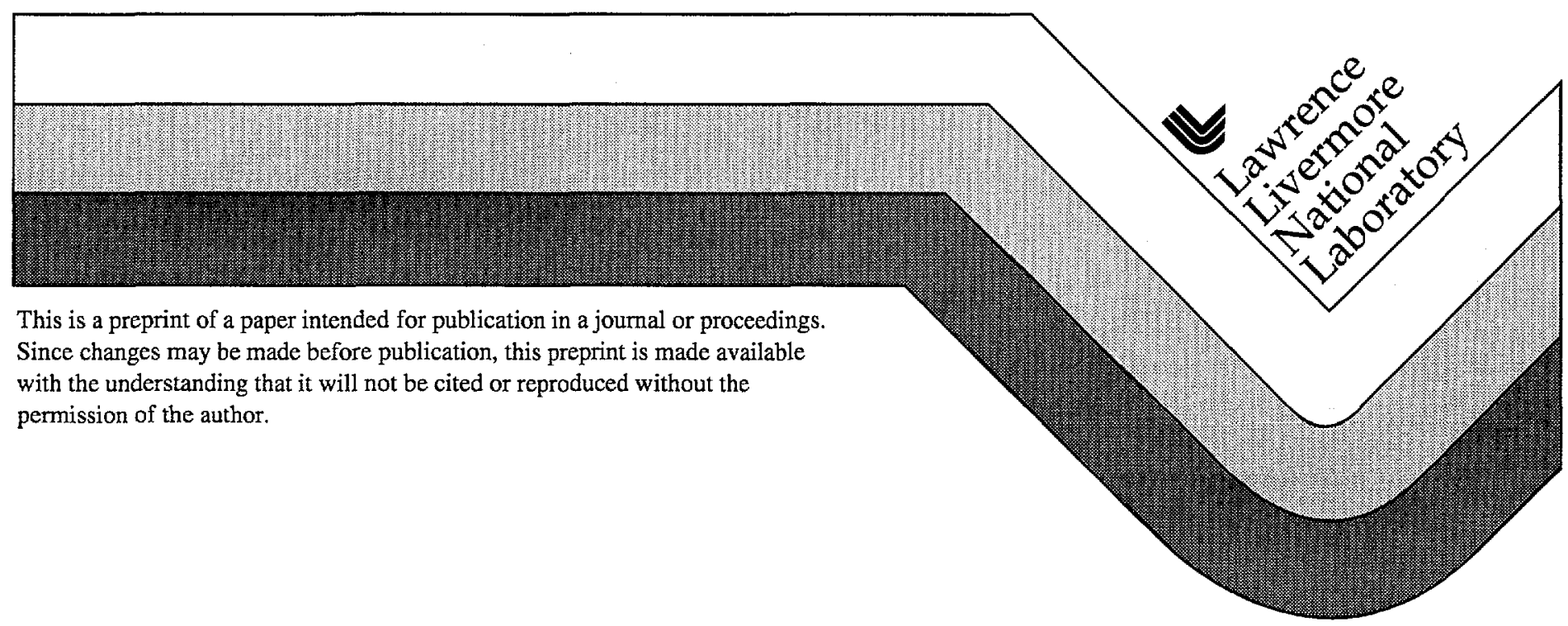




\section{DISCLAIMER}

This document was prepared as an account of work sponsored by an agency of the United States Government. Neither the United States Government nor the University of California nor any of their employees, makes any warranty, express or implied, or assumes any legal liability or responsibility for the accuracy, completeness, or usefulness of any information, apparatus, product, or process disclosed, or represents that its use would not infringe privately owned rights. Reference herein to any specific commercial product, process, or service by trade name, trademark, manufacturer, or otherwise, does not necessarily constitute or imply its endorsement, recommendation, or favoring by the United States Government or the University of California. The views and opinions of authors expressed herein do not necessarily state or reflect those of the United States Government or the University of California, and shall not be used for advertising or product endorsement purposes. 
Thermal-mechanical behavior of a heated $3 \mathrm{~m}$ block of fractured tuff

S. C. Blair

Lawrence Livermore National Laboratory, Livermore, California, U. S. A.

W. Lin

Lawrence Livermore National Laboratory, Livermore, California, U. S. A.

\begin{abstract}
This paper presents an overview of the geomechanical studies conducted at the Large Block Test at Fran Ridge, near Yucca Mountain, Nevada, and results of geomechanical observations made during the first 10 months of heating. This test is being conducted on a block of rock that is $3 \mathrm{~m} \mathrm{x} 3 \mathrm{~m}$ in cross-section and $4.5 \mathrm{~m}$ high. Heaters have been placed in the rock to simulate a plane heat source, $1.75 \mathrm{~m}$ above the base of the block. The 3-dimensional geomechanical response of the rock to the heating is being monitored using instrumentation mounted in boreholes and on the surface. Results show that thermal expansion of the block began a few hours after the start of heating. Moreover, expansion in the horizontal direction is consistent with opening of vertical fractures. Opening and sliding of fractures has been correlated with anomalous temperature behavior, indicating that fracture deformation influences the hydrothermal behavior.
\end{abstract}


The Yucca Mountain Site Characterization Project is investigating Yucca Mountain, Nevada, as a potential repository for high-level nuclear waste. When emplaced in a repository, the radioactive decay heat of the waste may cause coupled thermal-mechanical-hydrologicalchemical (TMHC) processes in the rock forming the near-field region of a repository. These processes must be understood before model calculations can be performed to confidently predict the performance of a repository over time.

Efforts to understand and characterize coupled processes in a fractured rock mass include the Large Block Test (LBT) currently underway at Fran Ridge, near Yucca Mountain, Nevada. The Large Block Test is being conducted on a rectangular prism of rock that is $3 \mathrm{~m} \times 3 \mathrm{~m}$ in cross-section and $4.5 \mathrm{~m}$ high. It is a fractured rock mass that was exposed from an outcrop by excavating the surrounding rock, leaving the rectangular prism (see Figure 1). Two sub-vertical sets of fractures and one set of sub-horizontal fractures intersect the block. The sub-vertical fracture sets are approximately orthogonal, with spacing of 0.25 to $1 \mathrm{~m}$ and are oriented generally in the NE-SW and NW-SE directions. In addition, the block contains one major sub-horizontal fracture located approximately $0.5 \mathrm{~m}$ below the top surface. This fracture is visible in Figure 1.

The objective of the LBT is to create, maintain and observe a planar, horizontal region of boiling in the block, so as to observe coupled THMC behavior in a fractured rock mass (Lin et al., 1995). Specifically, the LBT will study the dominant heat transfer mechanism, condensate refluxing, re-wetting of the dry-out zone following the cool-down of the block,

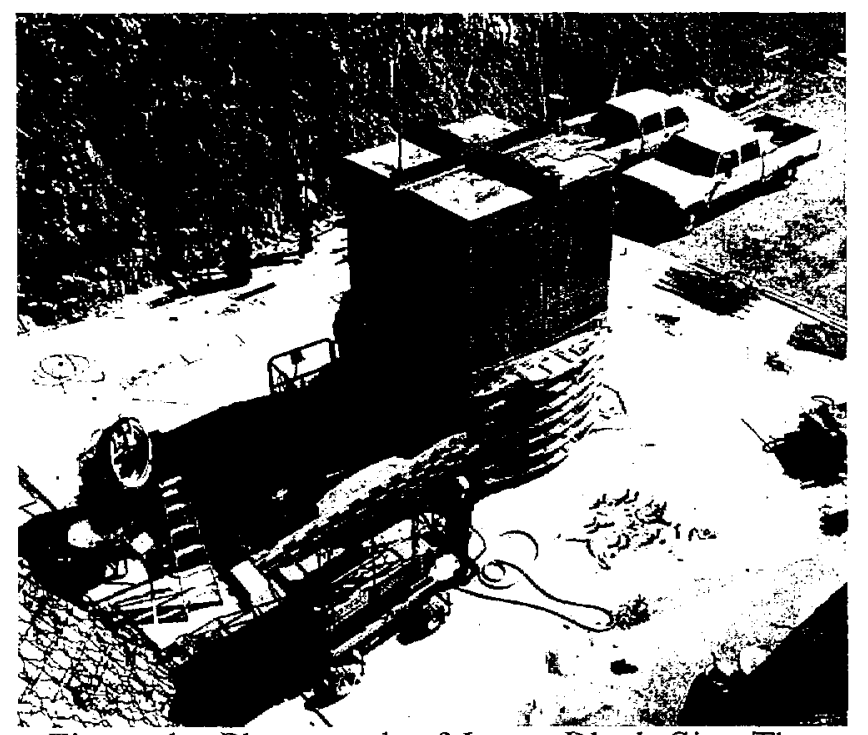

Figure 1: Photograph of Large Block Site. The upper portion of the block is exposed while the lower portion is supported with bracing $\mathrm{T}$ shaped grooves on face are locations of fracture monitors. displacement of fractures, and rock-water interaction. One particular goal of the test is to assess how episodes of opening or shear displacement along fractures are related to changes in the thermal-hydrologic behavior of the rock mass. To this end heaters have been placed in the rock to simulate a plane heat source at a height of $1.75 \mathrm{~m}$ from the base of the block, and a steel plate fitted with heating/cooling coils has been mounted on the top of the block. This plate is connected to a heat exchanger to allow thermal control of the top surface.

\section{INSTRUMENTATION}

The 3-dimensional geomechanical response of the rock to the heating is being monitored using borehole extensometers and surface mounted fracture gauges. Multiple-point-borehole extensometers have been deployed in a total of 6 boreholes, 2 of these are horizontal with an E-W orientation, 3 are horizontal with a $\mathrm{N}-\mathrm{S}$ orientation, and 1 is vertical. The locations of these holes and MPBX anchors in them are shown in Figure 2.

Deformation across fractures that intersect the surface is being monitored using 3-component fracture monitors that have been installed at 17 locations on the surface of the block as shown in Figure 3. A few of the fracture monitor locations are visible as T-shaped grooves in Figure 1.

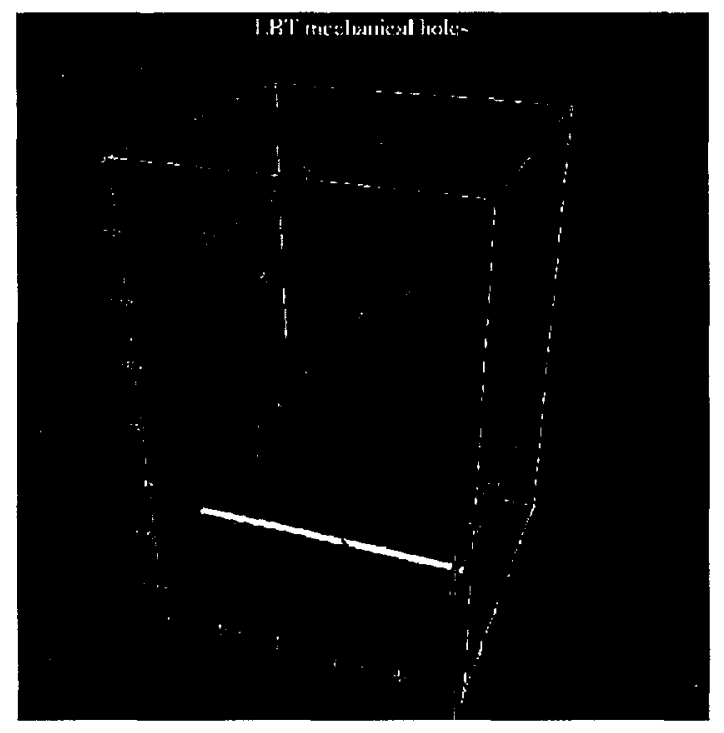

Figure 2: Location of boreholes in Large Block Test used for MPBX measurements. Perspective view is from the Southeast looking Northwest. MPBX anchor locations are shown as disks concentric with the boreholes. Also shown are one observation hole (bright white), and a major fracture plan trending NW-SE. 
Fracture deformation at the surface is monitored as follows. One major sub-vertical fracture on each face was chosen for monitoring based on geological mapping studies of the block. Fracture monitors were installed at 3 or 4 locations along the trace of each of the chosen fractures. In addition, motion on the large sub-horizontal fracture near the top of the block is being monitored using one fracture monitor on each face. The fracture monitors measure movement in directions across the fracture, and along the trace of the fracture both parallel and perpendicular to the face. Temperature and fluid movement in the block are also being monitored, and the geomechanical data are being interpreted in conjunction with these other data sets.

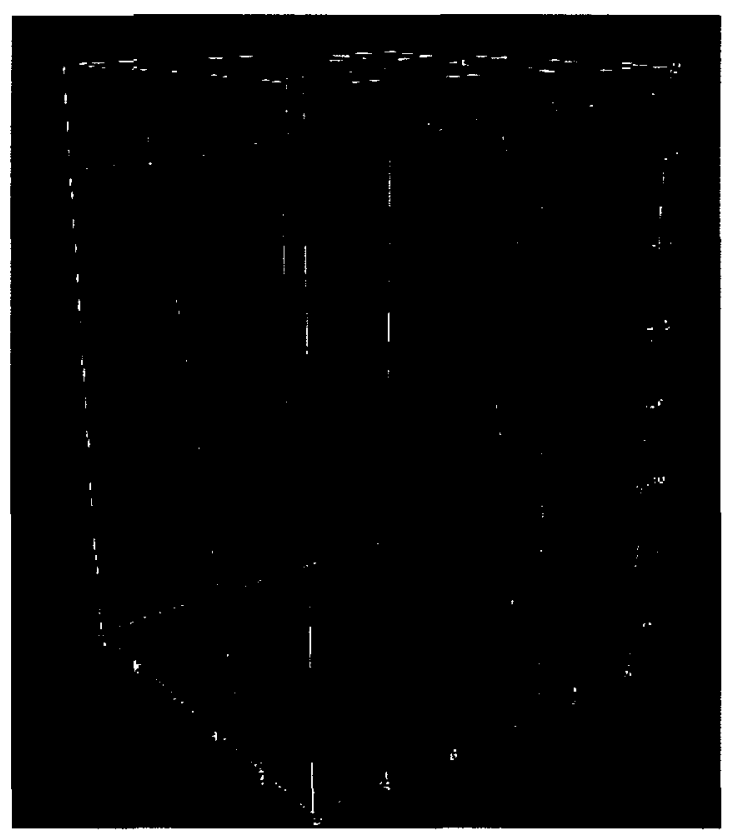

Figure 3. Locations of surface mounted fracture monitors.

\section{RESULTS}

Heating of the block was started on Feb. 27, 1997, and temperature vs. time measured near the center of the heater plane is shown in Figure 4. This figure shows temperature increased from ambient to $90^{\circ} \mathrm{C}$ in the first few hundred hours of heating. A power outage caused a drop in temperature at approximately 600 hours. When power was restored temperatures quickly rose back to pre-outage levels, and near the heater temperature reached approximately $98^{\circ} \mathrm{C}$ after 750 hours of heating. After $800 \mathrm{hr}$. temperature continued to rise more gradually reaching nearly $120^{\circ} \mathrm{C}$, until 2520 hours when a broad thermal disturbance occurred. Figure 4 shows that the temperature dropped sharply to approximately
$100{ }^{\circ} \mathrm{C}$. It is important to note that while data for only one temperature sensor are shown in Figure 4, temperatures at several locations in the block jumped to $100^{\circ} \mathrm{C}$ at this time. Temperatures remained at this level for about 400 hours and then gradually recovered to levels consistent with those observed prior to $2520 \mathrm{hr}$. At $4475 \mathrm{hr}$. temperature suddenly dropped to $100^{\circ} \mathrm{C}$ for a second time. However, in this case the temperature recovered after approximately $200 \mathrm{hr}$. These temperature observations are consistent with the formation of transient heat-pipes within the block. At approximately $5000 \mathrm{hr}$. the temperature decreases and then becomes steady at approximately $135^{\circ} \mathrm{C}$. This is associated with a change in the power supplied to the heaters.

The overall temperature profile is consistent with conduction dominated heat flow in the block, except for the temperature excursions at 2520 and 4475 hours. These excursions are thought to be breakdowns in the metastable hydrothermal field and formation of transient heat-pipes. While is appears that these thermal anomalies are associated with increased infiltration, thermalmechanical deformation of fractures, or other changes in the macroscopic flow system, the exact mechanism of their behavior is poorly understood.

Preliminary analysis of deformation has been conducted using data from the MPBX and fracture monitor systems. Results from both these systems show that within a few hours of the heater start-up the block started expanding. This is clearly illustrated in Figure 5 which shows data from one of the MPBX holes that is oriented in the East-West direction. In this figure anchor 0 is at the West face and and anchor 4 is at the bottom of the horizontal hole. Thus, the total deformation observed is approximately 0.01 Overall horizontal deformation of the block after $937 \mathrm{hr}$. is shown in Table 1. This table shows similar amounts of expansion in both the E-W and $\mathrm{N}-\mathrm{S}$ directions and that expansion in both horizontal directions is a linear function of height above the base. This is in disagreement with the continuum calculations of Blair et al., 1996 which predicted a non-linear profile of horizontal deformation with height associated with the vertical thermal gradient imposed on the block. Moreover, MPBX data from boreholes in the upper third show that most of the deformation occurs in discrete vertically oriented zones. This may be caused by opening of vertical fractures in this upper region. The observed displacements for the central one third of the block, is in good agreement with predicted values for this zone. Finally, deformation in the lower third of the block is small. This is consistent with the predicted thermal expansion. Data for one of the horizontal holes also indicate that deformation is occurring in a discrete vertically oriented zone. Data also indicate 


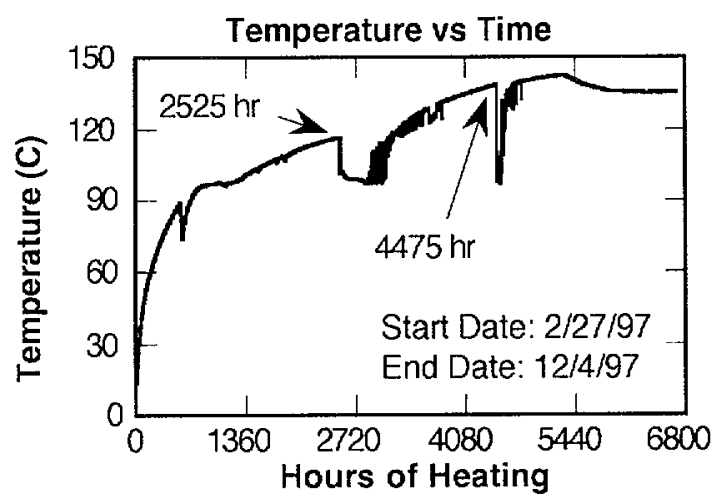

Figure 4. Temperature vs. time for thermocouple located slightly above the heater plane for the Large Block Test.

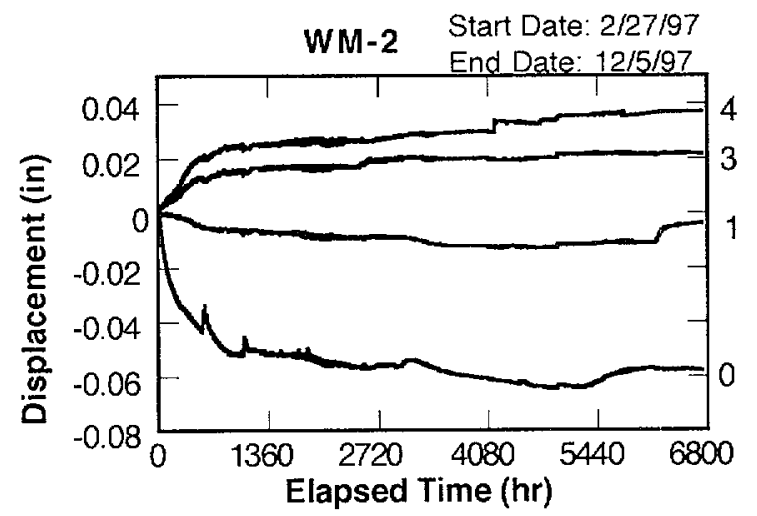

Figure 5. Deformation in E-W direction, recorded using an MPBX system referenced to the center of the block. Numbers at right indicate relative position of anchor.

Table 1. Overall deformation at 937 hours measured using MPBX systems.

\begin{tabular}{cccc} 
Direction & Hole & Height (in) & Expansion (in) \\
\hline E-W & WM-1 & 18 & 0.023 \\
N-S & NM-1 & 23 & 0.023 \\
N-S & NM-2 & 77 & 0.049 \\
E-W & WM-2 & 126 & 0.076 \\
N-S & NM-3 & 138 & 0.086
\end{tabular}

that deformation in the vertical direction is less than that observed in the horizontal direction, and that the region of the block above the heaters is moving upward as a unit.

Results from the fracture monitors are consistent with those from the MPBX in that the fractures are generally opening. The overall change in aperture measured at each location is shown in Figure 6 . Figure 6a shows that several of the fractures opened between 0.05 and 0.015 in., and that closure of some
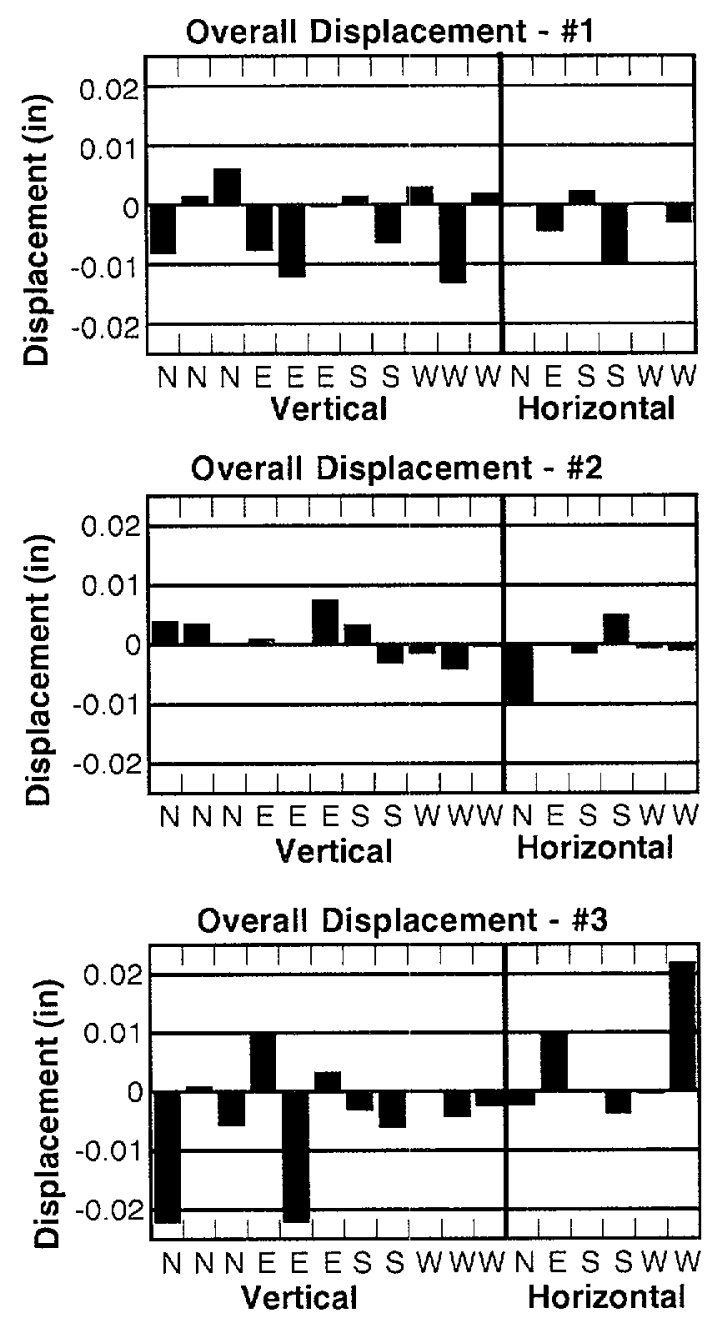

Figure 6. Total displacement observed on selected fractures; (a) changes in aperture (opening is negative), (b) shear parallel to face, (c) shear normal to face.

fractures was observed. Figures $6 \mathrm{~b}$ and $6 \mathrm{c}$ show overall shear movement on the fractures. This figure shows that shear displacements both parallel and perpendicular the faces are both fewer and smaller than normal displacements across the fractures. The large horizontal fracture near the top of the block does show shear offset to the face of the block. This figure shows these to be the largest movements. This is consistent with overall lateral expansion of the block discussed above.

The overall displacements on the block are shown in Figure 7. One of the most prominent fractures observed on the block is a sub-horizontal fracture about $50 \mathrm{~cm}$ from the top of the block. Fracture monitor data show that all of the rock above this fracture is moving to the east as a unit. Another major fracture is a North-South trending subvertical fracture 


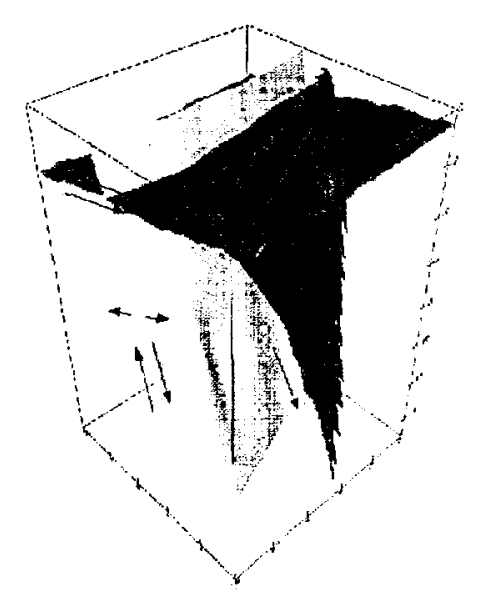

Figure 7. Overall motions observed for Large Block

that divides the block vertically into eastern and western sub-blocks. Data for this fracture indicate the eastern sub-block is moving upward with respect to the western sub-block.

As mentioned above, one of the goals of the LBT is to study coupled T-H-M processes, and it is interesting to note that the thermal excursion at $2520 \mathrm{hr}$. was preceded by increased motion on several of the fracture monitors, which indicates that the sudden drop in temperature may be related to a change in the fracture flow network. Displacements measured by the fracture monitors for $2500-2550 \mathrm{hr}$. is show in Figure 6a-c. This Figure shows that significant motion on the large horizontal fracture can be associated with the thermal excursion. More detailed analysis indicates that unlike the thermal response, the motion on this fracture was distributed in time and space. The onset of fracture deformation preceded the thermal event by between 10 and 15 hours.

\section{CONCLUSIONS AND SUMMARY}

In summary, the thermomechanical response of the Large Block has been monitored using MPBX and surface mounted fracture monitors. Thermal expansion of the block was evident a few hours after the start of heating. This is verified by data recorded on the fracture monitors and MPBX systems. MPBX data indicate that the block has expanded in the horizontal direction, ant that this expansion is a linear function of the height above the base of the block. Expansion at the top of the block greater than was estimated using continuum assumptions, and much of
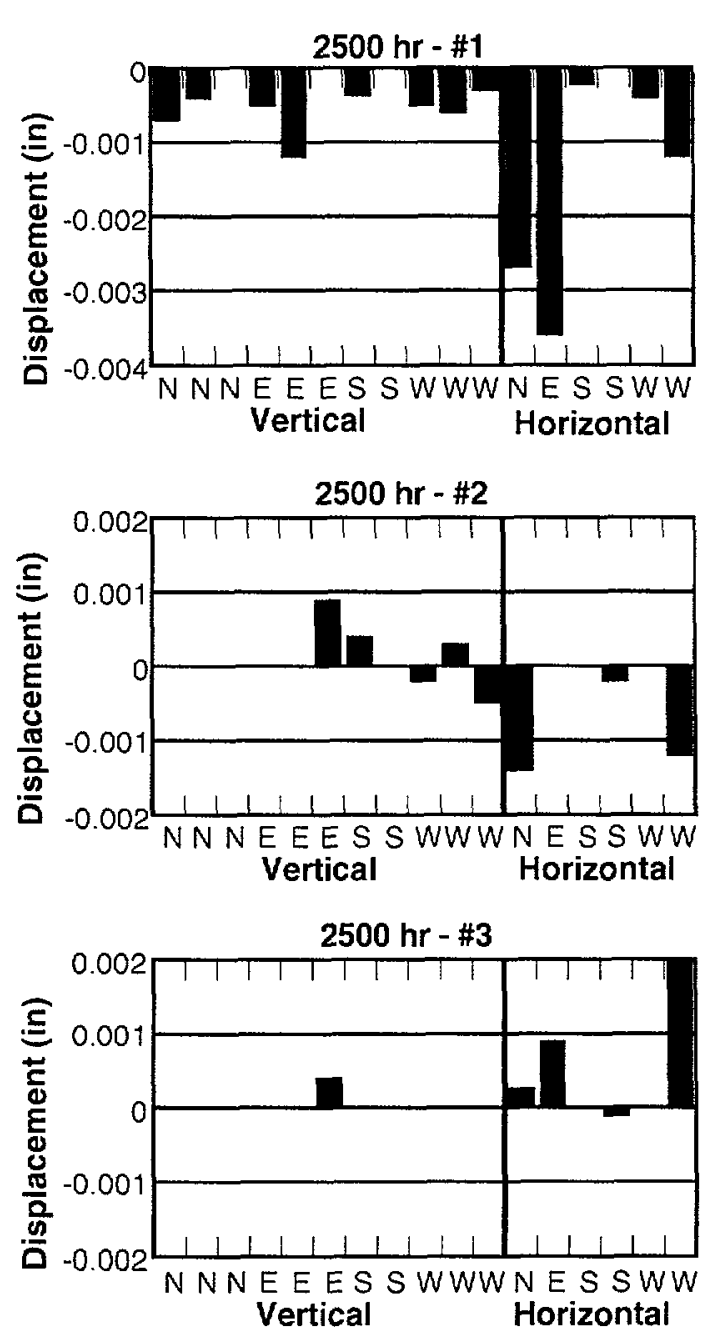

Figure 8. Fracture displacements observed from 2500$2550 \mathrm{hr}$. (a) changes in aperture (opening is negative), (b) shear displacement parallel to face, (c) shear displacement normal to face.

the deformation has taken place in discrete zones. This is consistent with opening of vertical fractures In the vertical direction, the upper two thirds of the block is extending as a unit.

The hydrothermal response of the block is expected to be dominated by flow in vertical fractures and it is surprising that the major thermal excursion at 2520 hours is associated primarily with movement on a horizontal fracture. It is also important to note that a rainstorm occurred at the site several hours prior to the thermal excursion at $2520 \mathrm{hr}$. and it is possible that the horizontal fracture served as a primary conduit for focusing water flow within the block. 


\section{REFERENCES}

Blair, S. C., P. A. Berge \& H. F. Wang (1996) "Geomechanical analysis of the Large Block Test", UCRL-ID 122898, Lawrence Livermore National Laboratory.

Lin, W. D.G. Wilder, J. A. Blink, S. C. Blair, T. A. Buscheck, W. E. Glassley, K. Lee, M. W. Owens, \& J. J. Roberts (1995) "A heated large block test for high level nuclear waste management", in Proceedings of the Second International Conference on the Mechanics of Jointed and Faulted Rock, Vienna, Austria.

This work was supported by the Yucca Mountain Site Characterization Project. Work periormed under the auspices of the U.S. Department of Energy by Iawrence Livermore National Laboratory under contract W-7405-ENG-48. 
Technical Information Department $\bullet$ Lawrence Livermore National Laboratory University of California $\bullet$ Livermore, California 94551

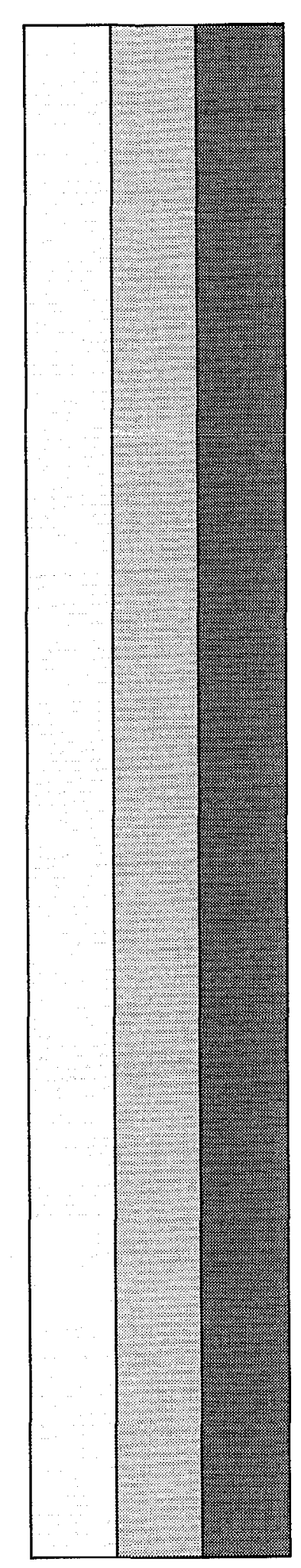

